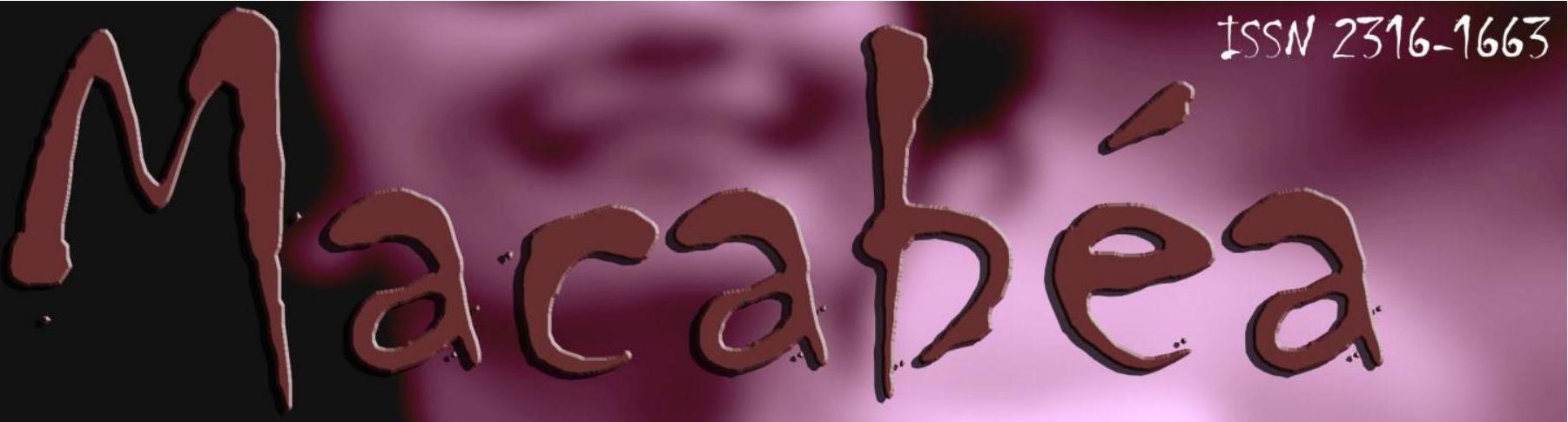

Revista Eletrônica do Netlli, Volume 7. Nümero 1. Jân. J Jul... 2018

\title{
UMA LEITURA TEMÁTICO-FIGURATIVA DE CANTOS DE LÚCIFER, DE JOSÉ ALCIDES PINTO
}

\section{A THEMATIC-FIGURATIVE READING OF CANTOS DE LÚCIFER, BY JOSÉ ALCIDES PINTO}

\author{
Ana Tamires da Silva Oliveira \\ UFC, Brasil
}

RESUMO | INDEXAÇÃO | TEXTO | REFERÊNCIAS | CITAR ESTE ARTIGO | O AUTOR RECEBIDO EM 17/10/2017 • APROVADO EM 04/07/2018

\begin{abstract}
This study aims to make a semiotic analysis of the book Cantos de Lucifer (1954) by the writer José Alcides Pinto, observing the outline of the thematic-figurative course that develops during the book. The analysis of the work will be made based on the Discursive Level of the Gerative Course of Sense developed by A. J. Greimas, having as a very specific focus the use of the thematization aspects and figurativization aspects of the discursive semantics. The studies of Barros (2005), Fiorin (2005) and Bertrand (2003) were also used as theoretical support in the analysis developed.
\end{abstract}

\section{Resumo}


Este estudo tem por objetivo fazer uma análise semiótica do livro Cantos de Lúcifer (1954) do escritor cearense José Alcides Pinto, observando o delineamento do percurso temáticofigurativo que se desenvolve durante o livro. A análise da obra será feita com base no Nível Discursivo do Percurso Gerativo de Sentido desenvolvido por A. J. Greimàs, tendo como foco bastante específico o uso dos aspectos de tematização e figurativização da semântica discursiva. Os estudos de Barros (2005), Fiorin (2005) e Bertrand (2003) também foram usados como suporte teórico na análise desenvolvida.

Entradas para indexação

KEYWORDS: Semiotic. Thematization. Figurativization. Cantos de Lúcifer.

PALAVRAS CHAVE: Semiótica. Tematização. Figurativização. Cantos de Lúcifer.

Texto integral

\section{INTRODUÇÃO}

Este estudo nasceu do desejo de se analisar à luz da teoria semiótica uma das obras do escritor cearense José Alcides Pinto. Tal análise será feita com base nos estudos da semiótica francesa, disseminada por Algirdas Julien Greimas (19171992). 0 percurso Gerativo de Sentido de Greimas é o modelo analítico desta análise, pois toda ela parte da aplicação dos conceitos de uma das etapas deste percurso gerador: o nível discursivo.

Cantos de Lúcifer (1954) é um dos primeiros livros publicados por José Alcides Pinto, trata-se de uma prosa poética (tendo sido considerado apenas como poesia por alguns críticos) desenvolvida ao longo de dezenove cantos em que parece desenvolver (esta é a nossa hipótese) um percurso temático que parte da ideia de condenação \inferno para a ideia de redenção \paraíso.

O que pretendemos mostar neste trabalho é que a semiótica consegue abarcar este percurso temático, identificandoas figuras que o sustentam, o que faz com que o texto seja encarado como "real", mesmo que sua atmosfera seja de irrealidade, fazendo com que no momento da leitura, o leitor possa encarar como uma realidade aquilo que o texto constrói e sustenta, por mais absurda que possa parecer.

A pesquisa desenvolvida neste artigo está dividida em duas seções, sendo a primeira intitulada de Um Breve Percurso Sobre a Teoria Semiótica do Texto. Como o próprio título aponta, tratará de explicar a teoria que será aplicada neste trabalho, para que o leitor compreenda e possa acompanhar a análise do texto literário bem inteirado da teoria apropriada. Tendo como suporte, para tanto, os estudos de Barros (2005), Fiorin (2005), Bertrand (2003) e outros que podem ser visualizados no campo de referências ao final do artigo. 
Na segunda seção, A Leitura Temático-figurativa de Cantos de Lúcifer, a obra será analisada através de trechos selecionados entre os dezenove cantos em que se organiza o texto literário, tendo por base os conceitos de tematização \tema e figurativização \figura da semântica discursiva que pertence ao terceiro nível do Percurso Gerativo de Sentido (PGS). Esperamos perceber as colaborações da relação entre temas e figuras, para o processo de construção de sentido e dos efeitos de realidade do texto de José Alcides Pinto (JAP).

A partir desta análise desenvolvida no decorrer das seções, objetiva-se ainda que este estudo seja importante para a valorização da escrita de JAP e trazer novamente às vistas a produção deste importante escritor brasileiro, sendo relevante, portanto, para obter um "panorama" característico da constituição temático-figurativa desta obra.

\section{UM BREVE PERCURSO SOBRE A TEORIA SEMIÓTICA DO TEXTO}

No campo dos estudos semióticos a construção do sentido pode ser representada por meio de um percurso gerativo. O Percurso Gerativo de Sentido então serve para explicar o delineamento da significação em textos, partindo de um patamar simples e abstrato na direção de algo mais complexo e concreto. Existem então três etapas que o compõem:

c) a primeira etapa do percurso, a mais simples e abstrata, recebe o nome de nível fundamental ou das estruturas fundamentais e nele surge a significação como uma oposição semântica mínima;

d) no segundo patamar, denominado nível narrativo ou das estruturas narrativas, organiza-se a narrativa, do ponto de vista de um sujeito;

e) o terceiro nível é o do discurso ou das estruturas discursivas em que a narrativa é assumida pelo sujeito da enunciação. (BARROS, p. 09).

O nível fundamental trabalha os conceitos de euforia (valor positivo) e disforia (valor negativo). No nível narrativo os valores ditos eufóricos e disfóricos serão assumidos por sujeitos em sua relação com objetos-valores, ( sendo ambos actantes). No nível discursivo se tem o exame das "instâncias da enunciação", em que se tem o nível mais próximo da manifestação do discurso.

É neste último nível, o nível mais superficial do percurso, em que se ancora esta análise. Sendo o nível de superfície, é onde residem estruturas bastante complexas e adensadas, na forma de temas e de figuras: "Ainda no nível discursivo, as oposições fundamentais, assumidas como valores narrativos, desenvolvem-se 
sob a forma de temas e, em muitos textos, concretizam-se por meio de figuras." (BARROS, 2005, p. 11). Dentro deste nível, portanto, nos deteremos nos conceitos de tematização e figurativização aplicados na análise de Cantos de Lúcifer (1954).

É necessário entendermos estes dois conceitos que serão aplicados. No Dicionário de Semiótica há a definição de que

Em semântica* discursiva, a tematização é um procedimento ainda pouco explorado que tomando valores* (da semântica fundamental) já atualizados (em junção* com os sujeitos*) pela semântica narrativa, os dissemina, de maneira mais ou menos difusa ou concentrada sob a forma de temas* pelos programas* $\mathrm{e}$ percursos narrativos* abrindo assim, caminho à sua eventual figurativização. (GREIMAS; COURTÉS, 2008, p. 454).

0 processo de tematização é um mecanismo de concretização do sentido, construído em determinado discurso. Dentro deste processo surgem os temas que permeiam o determinado texto. 0 tema vem a ser uma espécie de campo semântico que estabelece um conceito, um valor dentro do texto. Para Fiorin (2005) ele é "um investimento semântico, de natureza puramente conceitual, que não remete ao mundo natural. Temas são categorias que organizam, categorizam, ordenam os elementos do mundo natural [...]" (p. 91).

Sendo assim os temas podem ser um conceito, uma abstração categórica que pode ser preenchida com representações do mundo natural, concretas, sendo estas as figuras. Ainda seguindo o pensamento de Fiorin (2005), as figuras aparecem como uma forma de assimilar o mundo, enquanto os temas seriam uma forma de explicar esse mundo. Precisamos ter em mente que:

\begin{abstract}
A tematização expressa elementos abstratos buscando explicar a realidade e representar o mundo através de um revestimento conceitual. Os temas organizam, categorizam e ordenam a realidade significante de modo a permitir sua interpretação. Figuras e temas são para manter a coerência interna do texto, necessitam seguir um percurso ou encadeamento lógico de modo a gerar sentido. As figuras devem ser vistas através do conjunto por elas composto e não isoladamente. (BARBALHO, 2006, p. 51)
\end{abstract}

Como se nota, temas e figuras parecem ser instâncias que se complementam, ou seja, para que um significado seja construído no texto é necessário que um esteja ligado ao outro, porque "o nível temático dá sentido ao figurativo e o nível narrativo ilumina o temático [...] não há texto figurativo que não tenha nível temático subjacente, pois este é um patamar de concretização do sentido anterior à figurativização." (FIORIN, 2005, p. 94). 
A figurativização é o processo de representação de uma realidade sob o aspecto de figuras, que são os conteúdos de sistemas de representações que têm correspondência semântica com o mundo natural. A figura não tem significação própria, pois, se tratada como conceitos isolados, teremos a produção de ideias vagas e múltiplas já que o "seu sentido nasce do encadeamento com outras figuras, como se sabe, num texto, tudo é relação." (FIORIN; SAVIOLI, 2003, p. 79). Sendo assim, o sentido de um grupo de figuras será construído e organizado dentro de um tema.

A figuratividade estabelece uma rede de inter-relações onde enxergamos a organização das figuras no delineamento de um determinado tema ou de temas. Mas "a figuratividade não é mera ornamentação das coisas, é essa tela do parecer cuja virtude consiste em entreabrir, em deixar entrever, em razão de sua imperfeição ou por culpa dela, como que uma possibilidade de além-sentido." (GREIMAS, 2002, p.78). É a tela onde o discurso pinta seu referente, sua realidade.

No momento em que nos deparamos com textos figurativos é necessário encontrar o tema ou os temas que subjazem às figuras, pois elas são a concretização de tais temas que, por sua vez, revestem o esquema narrativo. Porque,

As figuras do texto formam uma rede, uma trama e, para entender esta trama, é necessário conhecer primeiro o nível temático, que, como o nível figurativo, são palavras e expressões que apresentam traços comuns de significação e que podem ser agrupados. (ARRAIS; LIMA; ALBUQUERQUE, 2013, p. 157).

Esta ideia de uma necessária complementação para a obtenção do sentido do texto é o que vamos perceber também na obra que analisamos, pois esta relação de interdependência parece produzir um percurso que vai se incorporando e dando um sentido completo ao texto, conferindo a ele o efeito de realidade desejado pelo idealizador do discurso. Desta forma, no momento da leitura, o leitor esteja imerso numa atmosfera real; mesmo que tenha contornos do fantástico. Sobre isto, diz Bertrand (2003): "o efeito produzido por ocasiões da leitura pode ser o de "realidade", mas também "irrealidade" ou "surrealidade" (p.162), como é o caso de Cantos de Lúcifer.

\section{A LEITURA TEMÁTICO-FIGURATIVA DE CANTOS DE LÚCIFER}

Em Cantos de Lúcifer (1954) temos a existência de um narrador que também é personagem contando o caminho que traça em direção ao paraíso. No começo da história o sujeito aparece envolto numa atmosfera de condenação, se encontra no inferno e narra seus infortúnios, seus pecados que o fizeram estar ali. No momento da narração de seus pecados e faltas, teremos na verdade, uma confissão desse 
sujeito que a partir do ato confessional ensaia uma mudança de estado, até enfim concretizá-la, sendo aceito no Éden.

Esse sujeito sofre uma transformação de estado, enquanto o discurso manifestado traz a ideia de inferno o sujeito está em disjunção com o que chamaremos de "salvação", quando o discurso passa a ideia de paraíso o sujeito entra em conjunção com a "salvação" de sua própria alma. Estes conceitos pertencem ao nível narrativo, porém ajudam a ilustrar os acontecimentos narrados e contribuem para endossar o que Fiorin (2005) afirma ao escrever que as figuras e temas são "o revestimento de um esquema narrativo" (p. 12).

Cantos de Lúcifer é escrito ao longo de dezenove cantos, cada um desses cantos recebe um título e um texto referente a ele, semelhante às obras clássicas, em particular A Divina Comédia, de Dante.

Durante as leituras da obra ficou clara a existência de uma atmosfera fantástica. 0 discurso presente no texto é o de ser recém-chegado ao âmbito do "inferno". Um fato interessante é que em determinado momento o discurso do sujeito parece assumir outro contorno,pois o ser que fala revela um tom de arrependimento, de confissão. Depois da confissão os sofrimentos se abrandam e o texto se converte em uma caminhada para o "Éden", o paraíso que o sujeito ganha o direito de habitar, depois de purificado.

Percebemos então, um percurso que esse sujeito traça durante os cantos, o texto mesmo mostra essa transição entre inferno e paraíso. Na semântica discursiva vamos perceber como esse percurso é uma forma de gerar o sentido que o discurso propõe. Através deste recorte da teoria semiótica do texto vamos trazer à tona o tema ou os temas que se constrói no texto literário e as figuras que os preenchem.

0 texto tem um traço central onde se ancoram os temas e suas figuras, a este traço central chamaremos de isotopia regente, tendo em mente que isotopia "designa em semiótica discursiva a permanência de um efeito de sentido ao longo da cadeia do discurso." (BERTRAND, 2003, p. 153). No livro Cantos de Lúcifer, percebemos três temas fundamentais; são eles: "Inferno", "Purgatório" e "Paraíso". Tais temas estão correlacionados neste traço isotópico que causa o efeito de sentido de "redenção" ao longo do texto alcidiano.

Para a melhor visualização destes temas foram escolhidos trechos da obra, cinco cantos que irão ilustrar cada um deles. Os primeiros trechos escolhidos montam um campo semântico que constrói a ideia de "inferno" dentro do texto, trata-se do décimo terceiro canto e do décimo quinto (respectivamente), vamos a eles:

\section{DO RELATIVO AO ABSOLUTO}

“[...] Ó mil demônios... Oh! A minha língua seca, vira cinza, ao calor da mais alta pressão dos mil fornos do inferno." ( PINTO, 2003, p. 52 , grifo nosso). 
As palavras que aparecem em negrito são as figuras que preenchem o tema inferno. Concretizado pelas figuras: seca-cinza - calor - fornos do inferno. Elas fazem clarear no leitor a ideia de inferno como um lugar de martírio, quente, sem água, sem nenhum alívio. 0 seguinte trecho ainda retoma ao mesmo tema de agora, mas traz figuras diferentes; já no título vemos a confirmação de tal tema.

\section{MARTÍRIO}

[...] estou pobre, meu Deus. Pobre e ulceroso como Lázaro, igual a um mendigo, confesso. Todo o meu contentamento vem da morte. Mesmo o de beijar-te o coração, a boca sanguínea, os olhos que não cessam de chorar, as mãos, o dorso, os pés de infeliz asceta, condenados a transportar a angústia infinita no rosto. Oh! o sangue da alma, criatura, sufoca-nos. (PINT0, 2003, p.54, grifo nosso).

As figuras deste trecho do canto remetem à imagens concretas de sofrimento que o primeiro trecho antevê, temos então as figuras bem marcadas: martírio - pobre e ulceroso como lázaro, remetendo ao episódio bíblico do mendigo Lázaro. 0 processo de figurativização continua com: morte - boca sanguínea - olhos que não cessam de chorar - os pés de infeliz asceta - condenados - angústia infinita - sufocanos.

No decorrer dos cantos começa a se delinear outro viés temático, os sofrimentos dão lugar a um desejo de purificação dos pecados, temos o tema "Purgatório" que aparece bem marcado no quarto canto do livro.

\section{IMAGEM}

Senhor, ensina-me toda a casta de vícios sórdidos, para que se instale em meu peito o ato da mais vil compaixão. 0 mal, como o crime, reclama contrição. Prometo, Senhor, ser o mais devasso de vossos filhos, para que me acedas o perdão que apaga as nódoas, limpa o sangue das mãos, varre para distante as sombras negras do coração. Que seriam dos perversos, Senhor, se não obtivessem o vosso divino perdão? Como sois, em verdade, misericordioso. (PINTO, 2003, p. 43, grifo nosso).

O desejo de contrição acentua um começo de mudança do estado do sujeito, até então condenado, o sujeito clama pelo "Senhor" e espera um perdão. As figuras que permeiam este tema são as seguintes: "compaixão - contrição - me acedas o perdão - apaga as nódoas - limpa o sangue - varre para distante - divino perdão misericordioso." as figuras remetem ao tema da purgação, traz a ideia de limpeza. 
A purgação dos pecados levam o sujeito a chegar ao destino final do percurso, ao paraíso. Ao que tudo indica o Senhor ao qual suplicou no trecho anterior concedeu ao sujeito a redenção e um lugar no paraíso. São dois os trechos que ilustram esse tema, o décimo oitavo e décimo nono cantos, respectivamente:

\section{VISÃO}

Lúcifer!_ó condenado! A razão está comigo e com os deuses. Alimentamo-nos de verdades celestes. Corrigi meus erros. Conquistei o terror à morte. Pobre Satanás! Pertenço ao reino de Cristo. Perdeste uma grande alma, apesar de toda a tua prudência. (PINTO, 2003, p. 57, grifo nosso).

\section{SISTEMA}

Estou com a medalha na boca. Estou soluçando. Estou lúcido. Estou nu. [...] Vêde! Caminho para o Éden. Enfim, caminho para o Éden. (PINTO, 2003, p. 58, grifo nosso).

O tema paraíso é revestido pelas seguintes figuras que o sustenta, em 'Visão' temos: deuses - celestes - corrigi meus erros - pertenço ao reino de Cristo. 0 sujeito agora chega ao momento final da transformação do seu estado, a chegada ao paraíso, ou seja, o fim dos sofrimentos, a conquista de tranquilidade no Éden. Este fato se concretiza em 'Sistema' através das figuras: estou com a medalha - lúcido - nu caminho para o Éden. Neste trecho ainda há um ponto importante que assegura o término do percurso do sujeito e sua transformação final, quando diz "Enfim, caminho para o Éden." A palavra "Enfim" marca a chegada e a concretização da transformação de estado.

Chegando ao final desta análise, percebemos que as figuras destacadas em cada trecho se harmonizam dentro de seus temas, porque "cada unidade faz de uma outra seu plano de referência, em que ela seleciona os elementos que a atualiza, e que em compensação a confirmam. Tal processo tem o efeito de reforçar o coeficiente de realidade de cada uma delas, "referenciando-as reciprocamente."(BERTRAND, 2003, p. 162).

Essa referenciação recíproca fica clara em Cantos de Lúcifer (1954), pois os cantos não obedecem um percurso linear, há progressões e digressões dos temas de inferno e purgatório até desembocar no paraíso, dando a ideia de que o texto é uma trama, pois cada linha temática se conecta para formar um todo de sentido, um referente, uma realidade.

\section{CONSIDERAÇÕES FINAIS}


Na construção deste trabalho, partimos da hipótese de haver um percurso temático central em Cantos de Lúcifer (1954) que regem outros três temas que chamamos de Inferno - Purgatório - Paraíso. Este percurso central que permanece em todo o texto literário, nomeamos de isotopia de redenção.

A confirmação das hipóteses veio da investigação das figuras que preenchem os temas da obra. 0 que percebemos é que se tratarmos cada tema como uma linha, teremos uma narrativa bem urdida, onde a trama é a construção do sentido. Tudo concorre dentro do texto para esse resultado e essas inter-relações entre temas e figuras estão amparadas nesta isotopia regente, no sentido pleno do texto.

Tendo mostrado isso durante a análise, percebemos que a escritura de José Alcides Pinto é um manancial de possibilidades para os estudos de semiótica, que o autor seja mais conhecido e reconhecido pela literatura que produziu com contornos do real, irreal e surreal.

\section{Referências}

ARRAIS, M. N. L.; LIMA, M. G.; ALBUQUERQUE, M. E. B. C. Discursivização DO Poema Cantar de Amor. InterScientia, João Pessoa, v.1, n.1, p. 150-165, jan./abr. 2013.

BARBALHO, C. R.S. Fazer Semiótico: subsídios para um exame do espaço concreto. Enc. Bibli.:R. Eletr. Bibliotecon. Ci. Inf.: Florianópolis, 2ํ número esp., p. 79-96, 2ํsem. 2006.

BARROS, D. L. P. Teoria Semiótica do Texto. São Paulo: Ática, 2005.

BERTRAND, D. Caminhos da Semiótica Literária. Bauru - SP: EDUSC, 2003.

COURTÉS, J. Introdução a semiótica narrativa e discursiva. Coimbra: Almedina, 1979.

FIORIN, J. L. Elementos da análise do discurso. São Paulo, 2005. ; SAVIOLI. Para entender o texto. São Paulo: Ática, 2003.

GREIMAS, A. J. Da imperfeição. Trad. Ana Cláudia M. A.Oliveira. São Paulo: Hacker, 2002. ; COURTÉS, J. Dicionário de Semiótica. São Paulo: Contexto, 2008.

\section{Para citar este artigo}

OLIVEIRA, Ana Tamires da Silva. Uma leitura temático-figurativa de Cantos de Lúcifer, de José Alcides Pinto. Macabéa - Revista Eletrônica do Netlli, Crato, v. 7., n. 1., JAN-JUN, 2018, p. 278287.

\section{A Autora}

Ana Tamires da Silva Oliveira possui graduação em Letras - Português pela Universidade Estadual Vale do Acaraú (2015). Atualmente é mestranda em Literatura Comparada pelo Programa de Pós Graduação em Letras da Universidade 
Federal do Ceará, desenvolvendo pesquisa sobre a obra do escritor José Alcides Pinto. Possui experiência profissional em Língua Portuguesa, Língua Espanhola e Biblioteca escolar. 